\title{
Jeffrey L. Kidder. Urbanflow: Bike Messengers and the City. Nueva York: Cornell University Press, 2011, 240 pp.
}

\author{
Natalia Mogollón ${ }^{1}$
}

El libro Urbanflow es una etnografía que se enmarca en el rubro de la sociología urbana, la cual nos invita a explorar la subcultura de los bicimensajeros o bike messengers en las ciudades norteamericanas. Para ello, el autor se pregunta cuál es el atractivo o el sentido de repartir paquetes, ya que, si bien no es un trabajo bien pagado ni mucho menos bien reconocido, ha sido un fenómeno en Estados Unidos de gran envergadura. Más aún, el autor busca entender por qué estos bicimensajeros pertenecen a una subcultura basada en su ocupación y qué es aquello que los une a su trabajo, incluso poniendo su vida en riesgo debido a las maniobras que realizan.

En ese sentido, el trabajo de campo se realizó en tres ciudades de Estados Unidos: Nueva York, Seattle y Los Ángeles, a lo largo de cinco años de los cuales tres fueron netamente de observación participante como su principal herramienta. Para la realización de su trabajo etnográfico el autor también empleó otros métodos importantes que le permitieron ahondar en el fenómeno de estudio: discusiones informales, entrevistas formales, y documentación histórica. Es importante resaltar que el autor no solo fue observador, sino que se convirtió en un bicimensajero y logró formar parte este mundo durante el período mencionado. Además, ello le permitió viajar a otras ciudades estadounidenses y formar parte de eventos de bicimensajeros, así como trabajar esporádicamente en dichos lugares.

\footnotetext{
1 Estudiante de sociología de la Facultad de Ciencias Sociales de la Pontificia Universidad Católica del Perú (PUCP). Correo electrónico: natalia.mogollonb@pucp.pe
} 
De este modo, Kidder primero realiza una aproximación al contexto de los bicimensajeros en Estados Unidos desde sus inicios, en la primera ola del urbanismo industrial. El autor nos muestra que inicialmente los bicimensajeros realizaban el trabajo de enviar encargos a distintas partes de la ciudad; no obstante, con la aparición de las tecnologías y la llegada de la globalización, el mundo se transformó y cada vez fue menos necesario el trabajo de estos mensajeros. De ahí que el autor se cuestione cómo es que hoy en día, incluso en los centros urbanos más prósperos, se requiera trabajo informal y de baja tecnología como los bicimensajeros. Este trabajo, como ha sido caracterizado en el libro, no posee ningún tipo de seguro laboral, no se verifica ni obliga el uso de implementos de protección como cascos o rodilleras, así como tampoco es una labor bien remunerada (entre 7 a 10 dólares la hora, aproximadamente), no obstante, quienes pertenecen a esta subcultura trabajar como mensajeros en bicicleta significa ser libres y amar lo que hacen. De este modo, el bicimensajero tiene que recorrer la ciudad con su bicicleta para hacer llegar el producto al destino indicado de la manera más rápida que pueda, atravesando todo el tráfico de la ciudad.

Así, mientras el autor se ha ido sumergiendo más en esta subcultura de los bicimensajeros, fue hallando dos componentes principales de esta subcultura que aborda en el libro: las emociones y el espacio. En el capítulo 2 y 3, Kidder nos muestra que las acciones y actitudes de los mensajeros no se reducen a simples necesidades económicas, sino que hay explicaciones que exceden estas razones, lo que genera esta subcultura que es parte del mundo social. En ese sentido, se establece formas de socializar entre los bicimensajeros que se basan principalmente en tomar cervezas luego del trabajo, montar bicicleta y asistir a los famosos alleycats o competencias informales de bicimensajeros. Del mismo modo, es un factor importante la gran presencia masculina en esta ocupación, pues si bien no hay restricciones en la inserción de mujeres, las cualidades que caracterizan este trabajo se califican bajo el concepto de dirty work por los peligros que conlleva montar bicicleta en medio del tráfico y que se ven enmarcados en un estigma sobre esta ocupación que se genera en la sociedad. De ahí que se vincule con las características masculinas principalmente.

Los capítulos 4 y 5 contienen una de las ideas principales para responder a los propósitos de la pregunta del autor. Según la experiencia recolectada, el autor sostiene que existe un sentimiento, al cual llama flow, que involucra la mente y el cuerpo y genera la creatividad y espontaneidad instintiva necesaria para lidiar con los monstruos del tráfico. Este elemento es lo que hace que el trabajo de estos individuos no sea aburrido y, por lo contrario, sea de disfrute completo, más aún en las calles de la ciudad. Para ello, el autor toma en cuenta el concepto de "efervescencia» de Durkheim para vincularlo con el sentimiento que surge en esta colectividad. 
La labor de los bicimensajeros no se trata exactamente de ir lo más rápido posible, sino de cómo lo hacen, es decir, las rutas y estrategias que utilizan. En este sentido, ponen su vida en riesgo al esquivar carros, peatones e incluso las luces rojas de los semáforos. Como sostiene Kidder, los mensajeros prueban sus habilidades, ya que por ello reciben una paga, pero principalmente porque es más divertido ir rápido (2011, p. 85).

No obstante, este flow que subyace al trabajo de los bicimensajeros no se produce solo individualmente, sino a través de interacciones sociales. Los alleycats o competencias informales refuerzan e internalizan el sentimiento colectivo, ya que son eventos que reúnen a bicimensajeros de todo el mundo y otorgan un valor afectivo a ese sentimiento. Así, muchos de los asistentes ni siquiera tienen el propósito de ganar las carreras, sino de disfrutar del evento y vivir la experiencia junto a otros participantes. Este ritual, no obstante, posee elementos simbólicos que también forman parte de este valor afectivo: la bicicleta, en ese sentido, cumple un rol importante. Más aun porque no solo tiene un significado en estas competencias, sino en el día a día de los bicimensajeros. Como también se sostiene a lo largo del libro, para quienes pertenecen a esta subcultura no solo es un estilo del momento, sino que se convierte en un estilo de vida en distintas formas, pues ya ni si quiera lo consideran un trabajo en sí mismo.

Los capítulos 6 y 7 tratan sobre cómo el espacio también es un factor relevante para la subcultura que se está estudiando, ya que esta se enmarca en lugares específicos, en este caso: las calles de la ciudad. Los bicimensajeros se apropian de la ciudad por medio de prácticas ritualizadas, así como de información que los educa para su salida a las calles. Es interesante cómo el autor propone la agencia de los mensajeros dentro de una estructura, sosteniéndose en contribuciones teóricas de Anthony Giddens. Así, vemos que los ciclistas son capaces de manipular creativamente su recorrido por la ciudad, situándose en un estado de liberación y limitación: limitante porque se encuentran expuestos a peligros y porque es poco claro los derechos que poseen los ciclistas, y liberador porque, al no tener un lugar oficial por donde manejar debido a la falta de ciclovías y una regulación, los ciclistas son libres de maniobrar donde mejor les convenga y deseen. De esta manera, los mensajeros se apropian del espacio usando la estructura material urbana y las reglas que gobiernan su uso para sus propósitos.

Pero los bicimensajeros no solo se apropian del espacio, sino que le dan un valor afectivo a este accionar a través de los símbolos. En ese sentido, el estilo de los mensajeros es la expresión más significativa del atractivo por repartir paquetes producida por el flow del ciclismo urbano. La posición que los mensajeros tienen en la sociedad también se caracteriza por un estado de liminalidad: son concebidos como «extraños» bajo los términos de Simmel debido a su característica de estar fuera de 
la ley que usualmente es percibida por la sociedad, lo cual significa una oportunidad - fuera de la ley_- pero que sigue representando la libertad que aclaman los bicimensajeros. Del mismo modo, otras acciones también son relevantes en el estilo de estos individuos: la prisa, la ropa — que es muy opuesta a la de los trabajadores de oficina-, las bicicletas sin frenos y la evasión del uso del casco. Entonces, vemos cómo un conjunto de elementos simbólicos se vincula con una carga emocional y con prácticas espaciales que las sostienen (Kidder, 2011, pp. 169).

En resumen, es interesante esta investigación etnográfica ya que profundiza en la identidad que se genera en esta subcultura de los bicimensajeros para que, lejos de seguir siendo estigmatizados por la sociedad como peligrosos o outlaw, el público pueda entender las razones y elementos que hay detrás y que impulsan a estos individuos a amar su ocupación y actuar de la manera en que actúan, incluso poniendo su vida en riesgo. Los dos elementos que el autor sitúa en el centro del argumento son el espacio y las emociones, las cuales se vinculan y otorgan un valor afectivo a las acciones que realizan, así como al espacio en el que se desenvuelven, es decir, las calles atiborradas de tráfico. De esta forma, el flow es el elemento crucial para los bicicmensajeros, pues no sienten su ocupación como tal sino como parte de su vida y disfrutan realizarla en plena «libertad», incluso considerando la ruta como un juego. 